\title{
POLYMORPHISM IN SEQUENCE OF PERMANENT TOOTH EMERGENCE IN CZECH CHILDREN
}

\author{
Romana Šindelářová', Zdeněk Broukal ${ }^{2}$ \\ 'Department of Orthodontics, Institute of Dental Medicine, First Medical Faculty, Charles University, Prague, Czech Republic \\ ${ }^{2}$ Department of Oral Epidemiology and Preventive Dentistry, Institute of Dental Medicine, First Medical Faculty, Charles University, Prague, \\ Czech Republic
}

\section{SUMMARY}

Objectives: The aim of the study is to determine norms of polymorphic variation in the sequence of permanent teeth in Czech children in order to establish first standards applicable to individuals. Setting out such standards, derived from the population to which they will be applied, are essential for diagnoses in paediatric dentistry, orthodontic treatment planning and for anthropological application.

Methods: Dental examinations were performed on a sample of 1,370 children ( 696 girls and 674 boys) aged 4-15 years. All emerged permanent teeth (other than third molars), when at least some part of crown has penetrated the oral mucosa, and the child's gender were recorded. The frequency of sequence polymorphism was calculated for each gender by counting instances of absent/present and present/absent across all possible intra-arch and inter-arch tooth pairs.

Results: Differential frequencies of polymorphic sequences were more common in the inter-arch tooth pairs than in the intra-arch pairs. The most similar frequencies in inter-arch pairs were observed in second mandibular premolar/second maxillary premolar in both genders. However, in the mandible there was a polymorphic sequence in the first molar/central incisor pair in both genders. Furthermore, mandibular polymorphisms were more commonly observed in the sequences of canine/second premolar in girls than in boys. Additionally, canine/second premolar polymorphic sequences were found to be more common in the maxilla in both genders.

Conclusions: The data presented in this article are useful in the prediction of tooth emergence sequence in individual Czech children and are important in paediatric dentistry and in orthodontic treatment.

Key words: polymorphism, sequence, permanent teeth, emergence time, Czech Republic, children

Address for correspondence: R. Šindelárová, Department of Orthodontics, School of Dentistry, First Medical Faculty, Charles University, Katerinnská 32, 12808 Prague, Czech Republic. E-mail: r.sindelarova@gmail.com

https://doi.org/10.21101/cejph.a5238

\section{INTRODUCTION}

The emergence times and sequences for permanent teeth are important factors in dental treatment planning, particularly in orthodontics, paediatric and forensic dentistry. Tooth eruption is defined as a process whereby the forming tooth moves from its intraosseous location in the jaw to its functional position in the oral cavity (1), but according to Demirjian (2) gingival emergence (often called eruption) represents only one stage in the process of eruption which is the first visible evidence of the tooth through the gingiva (3). The emergence of permanent teeth occurs in two stages. The first transitional period is characterized by the emergence of the first permanent molars and incisors, while in the second transitional period, canines, premolars and second permanent molars emerge.

Because of different environmental, ethnic and socioeconomic backgrounds, it is recommended to relate the variation in time of permanent tooth emergence to the population to which they are applied, e.g. in Africa teeth emerged earlier than in Asia (4). Because of this, there are many studies focusing on the investigation of standards specific to their own populations (5-10). The sequence of permanent teeth emergence in the studies (11-13) is formed by putting the tooth emergence age medians into an ascending order. This approach is overly simplistic and is considered inadequate for the accurate prediction of tooth emergence sequence in an individual due to the fact that frequencies in sequence variability have not been taken into consideration (8). The polymorphic variation standards in the sequence of tooth emergence outlined in this article would be more useful for dentists because they enable them to assess the normality/rarity of tooth sequence in an individual child.

The study aims at providing first standards for sequence polymorphism in permanent teeth emergence specific to the Czech population and has become a resource for dentists in identifying developmental abnormalities, treatment planning and in estimating dental ages for individual children.

\section{MATERIALS AND METHODS}

\section{Study Population}

The sample comprised 1,370 Czech children (696 girls and 674 boys) aged between 4 and 15. The data were collected in accord- 
ance with Act No. 101/2000 Coll. on the Protection of Personal Data and the study was approved by the Ethics Committee of the General University Hospital in Prague. Children examined in this research were also participants in a cross-sectional survey conducted over the years 2013 and 2014 in 11 elementary schools and kindergartens in the Czech Republic. Schools and kindergartens were pre-selected in accordance with WHO guidelines for national cross-sectional oral-health surveys whose aim was to study subjects in both urban and rural areas. After getting the principals' approval detailed information statements and informed consent forms were sent to the parents of the children selected. Out of the total number of children who consented to participate, only white Caucasians of European background were included in the study as representatives of the traditional Czech population.

\section{Data Collection}

Data was collected directly in the classroom. The children were examined for the emergence of permanent teeth by the main author of the study. A tooth defined as emerged had any part of it penetrating the gingiva and in this respect the outcomes were dichotomous: absent, where the tooth is not visible within the mouth, and present, where the tooth is clinically visible permanent tooth within the mouth). All emerged teeth (other than third molars), age and gender of the children were recorded. Teeth were identified according to the World Dental Federation (FDI) two-digit system (14).

\section{Statistical Data Analysis}

The analysis involved only the teeth on the right side, because there are no statistically significant differences in the timing of permanent contra-lateral pairs, as has been shown in numerous other studies $(13,15)$. All inter and intramaxillary tooth pairs of the combinations present/present, absent/absent, present/absent, absent/present were counted. The cases of present/present and absent/absent were then excluded, because they do not influence the sequence. Only instances of present/absent and absent/present, where frequencies of sequence polymorphism were found, were computed and then expressed as percentages. Frequencies of 5\% or higher are considered polymorphic and frequencies lower than $5 \%$ are rare. The statistical analysis was performed using statistical software IBM SPSS Statistics 23.

\section{RESULTS}

The results are presented in Table 1, which follows the same form as in similar studies on different populations $(7,9,16)$. In Table 1, teeth are ordered according to sequence determined by the median tooth emergence ages for Czech children, which differ in each gender. According to median age, the first transitional period begins with the emergence of the mandibular permanent central incisors in boys and the mandibular permanent molar in girls. The sequence of the second transitional period, based upon median age, is the same in both genders, with one exception: second premolars in the upper jaw emerge before canines in boys.

The polymorphic sequence of intermaxillary tooth pairs were present in cases 46/16 (87\%), 43/14 (68\%), 44/14 (7\%), 45/15
(57\%), 45/13 (81\%), 47/17 (65\%) in boys and 41/16 (83\%), 42/11(10\%), 42/21 (94\%), 43/14 (69\%), 44/14 (28\%), 45/13 (34\%), 45/15 (68\%), 47/17 (92\%) in girls. The highest polymorphic frequency was found in the pair $45 / 15$ in both genders (boys $57 \%$ and girls $68 \%$ ). For the maxillary arch there was a polymorphic sequence in the pair 13/15 in both genders (girls $77 \%$ and boys $23 \%$ ). Girls also had a marginal polymorphic sequence in the pair $11 / 16(10 \%)$. In the mandible there was a polymorphic sequence in the pair 46/41 in both genders (boys $46 \%$ and girls $54 \%$ ) and in the pair $44 / 43(13 \%)$ only in girls. Intra-arch sequence polymorphism was found to be more common in girls. In addition, sequence polymorphism in both jaws was not observed in the tooth pairs through the first and second transitional period (Table 1).

\section{DISCUSSION}

There are many approaches in determining the sequence of permanent teeth emergence. The simplest and most widely used model of constructing the sequence is based on placing the median age of individual teeth in ascending order. Nevertheless, this approach provides no information as to the frequencies of sequence variability (9) and therefore this model is considered misleading in evaluating tooth emergence sequences in individuals. In this study, the variability of tooth emergence sequence was determined in accordance with other studies $(9,16)$, which were based on the pairwise frequencies. Since it is a cross-sectional study, each child was examined only once and only pairwise frequencies were determined. The better approach would be a longitudinal study enabling the child to be observed over time (8) and would provide seven-teeth (except third molars) sequence frequencies instead of pairwise variations.

Given that this study was not intended clinically with access to X-ray examination but more anthropologically, neither agenesis nor retention of permanent teeth that could be recognized, clinically, as unerupted, could be observed. Agenesis of permanent teeth (excluding third molars) occurs in a range between 1.6-9.6\% of the general population; most often missing teeth (excluding third molars) are second lower premolars and second upper incisors (17). According to Holman and Jones, who focused on the effect of unrecorded agenetic teeth as potentially distorting results, a sufficiently representative sample of subjects does not lead to substantially distorted results (to measurement bias). In this study, they demonstrated that there was an overestimation of the average age at which teeth erupt irrespective of agenetic teeth which is less than $1 \%$, while the standard deviation in this study ranged between 3 and 5\%. According to these findings, agenesis can therefore be discounted (18). However, in our study, the sample group was sufficiently large to not expect agenetic teeth to affect the results. Because it is a cross-sectional study, it was not possible to assess the effect of premature loss of temporary teeth on permanent dentition emergence. Cross-sectional studies provide relatively good and on hand information (19) since we were able to work with a larger set of subjects and the risk of bias is also smaller when compared with longitudinal studies (20).

In the present study the possible association of the socioeconomics and permanent teeth emergence times has not been taken into account. Nevertheless, the relationship between socio- 


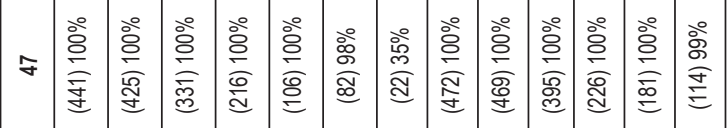

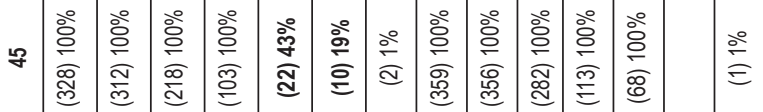

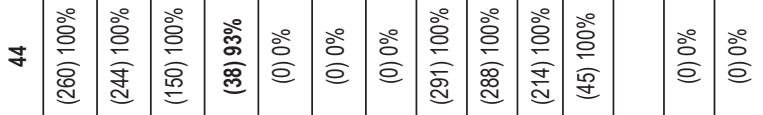

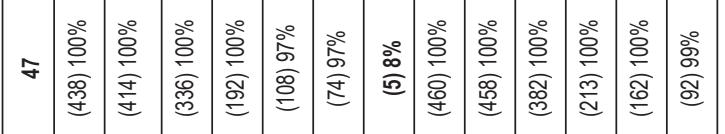

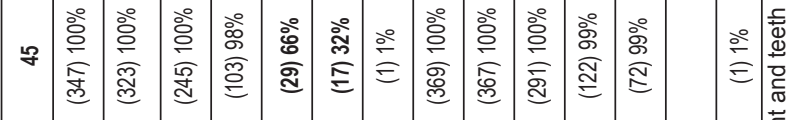

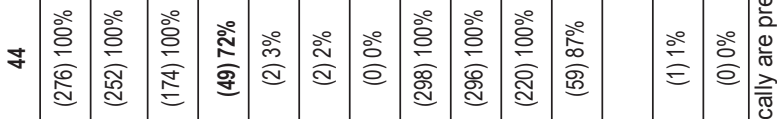

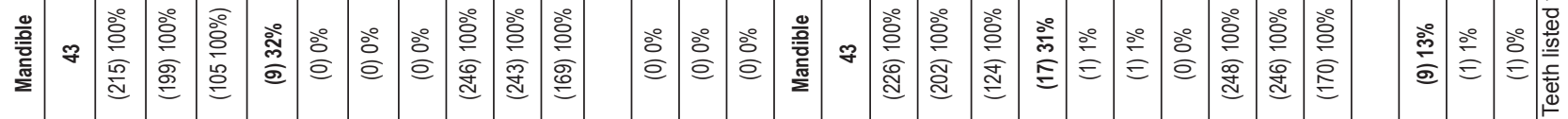

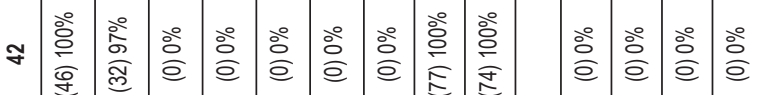

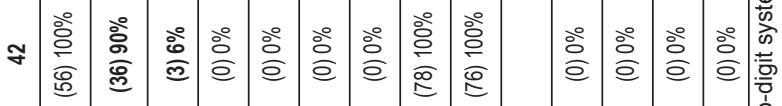

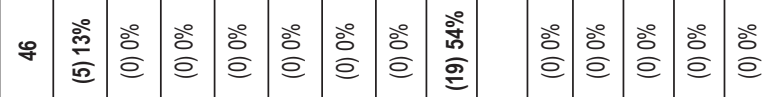

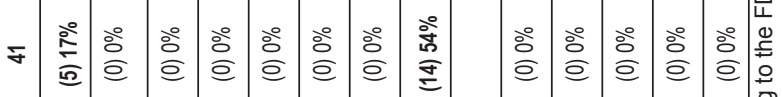

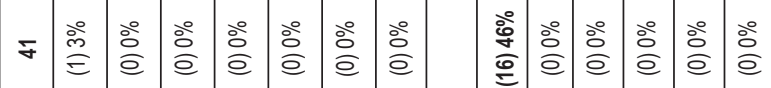

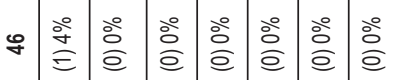

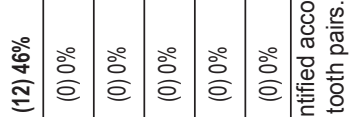

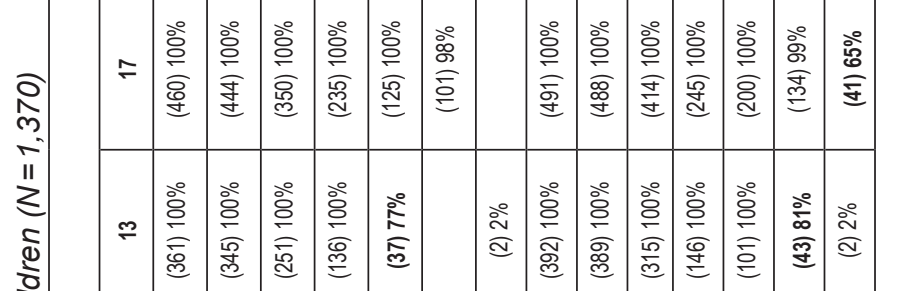

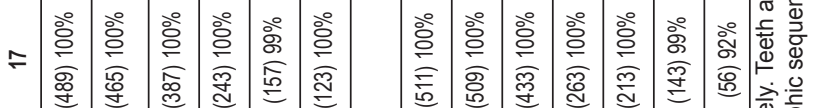

๘

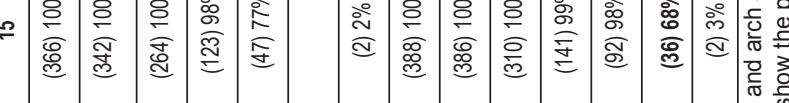

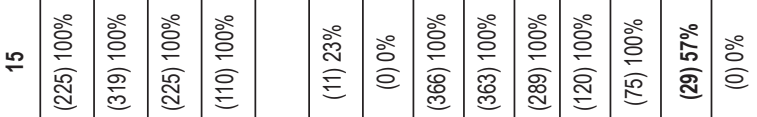

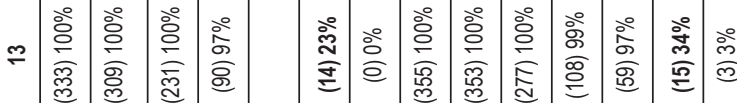

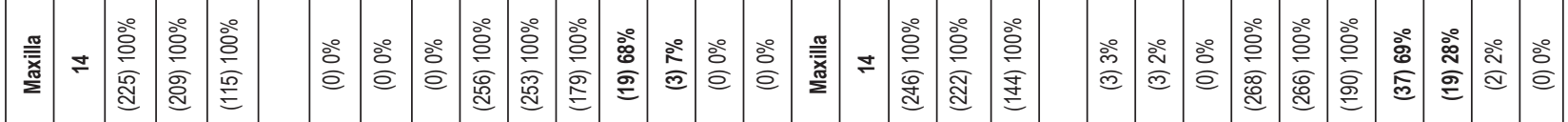

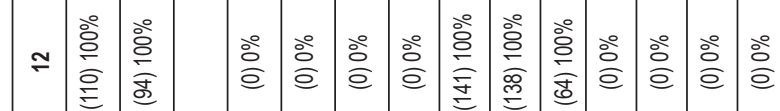

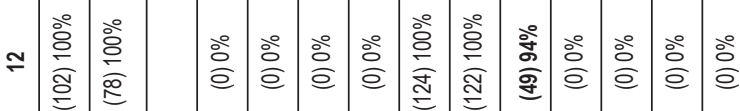

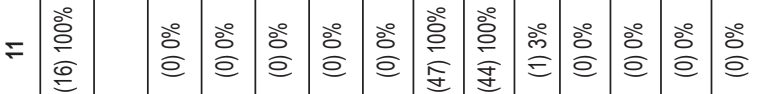

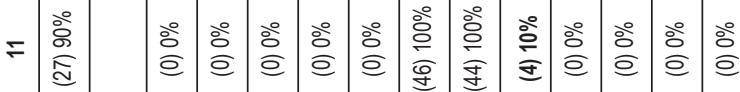

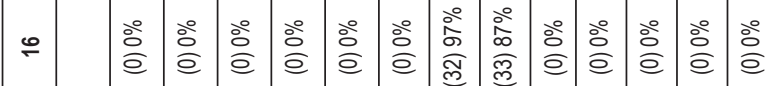

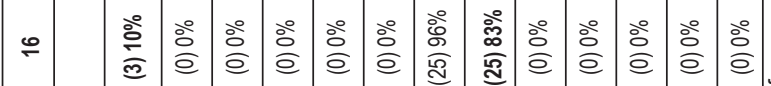

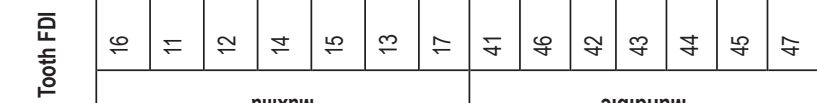

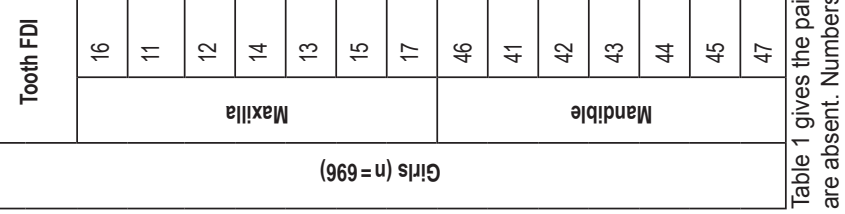


economics and childhood nutrition, as affecting the emergence of permanent teeth, has been discussed in the literature (21). In children of university-educated parents, in whom a higher standard of living is observed, teeth emerge earlier than in children of parents with lower education (22). It would be reasonable to assume that children from families with higher socioeconomic status might benefit from higher-quality healthcare and nutrition, resulting in faster development and emergence of permanent teeth. Conversely, children from families with lower socioeconomic status might be expected to suffer from less frequent visits and a lower-quality of dental care which may result in premature loss of deciduous teeth, which in turn has been found to affect the time of emergence of the permanent teeth (23). On the other hand, there are researchers that repudiate such associations $(11,24-26)$. The influence of socioeconomic factors on tooth emergence of Czech children will be the subject of future research.

An inter-examiner reliability test was not preformed, because all subjects were examined by the same researcher (the main author). Margin of error was not calculated, because Virtanen et al. (27) pointed out that the criteria distinguishing emerged (present) and non-emerged (absent) teeth are sufficiently delineated. In order to minimize other potential errors, the data were entered into the computer by one researcher (the main author) and checked by the other (the second author).

Due to the fact that our research was the first of its kind conducted in Europe and in the Czech Republic, it was not possible to compare our results with any available European data. Based on available studies, that also followed sequence variation expressing approach, it was possible to compare our results with those undertaken in Jordan (16), Australia (7) and the USA (9). All these studies showed similar results in maxilla. In upper jaw, the polymorphic variation was more common within the second transitional period and the sequence of polymorphism in the tooth pairs crossing the first and second transitional period was rare in both, boys and girls. The most common variable observed in our study was in the tooth pair $13 / 15$ in both genders. Although in our study the sequence of polymorphism was most commonly seen during the first transitional period in the lower jaw, in foreign studies it was seen during the second one $(7,16)$. The most common mandibular polymorphism for Australians and North Americans was the tooth pair 41/46 (9) and for Jordanians it was the tooth pair 44/43 (16). When we compared the polymorphism in upper and lower jaws, in the lower jaw the most common sequence was for the tooth pair $41 / 46$, which is consistent with other studies $(7,9,15)$. In the Jordanian study (16), the gender differences in the polymorphic variation were the most evident in lower jaw, the most differences were in the frequency of 44/43 tooth pair, being higher in boys, whereas in our results they were higher in girls. Frequencies of polymorphic sequences of tooth emergence in upper and lower jaws in girls and boys differ from the order determined by median age of tooth emergence. In girls the sequence is as follows: first premolar, canine, second premolar and second molar. In boys second premolars emerge before canines. The "incisor" pattern of tooth emergence, where in boys the replacement of deciduous teeth begins with the emergence of mandibular incisors, was observed not only in our study sample, but also in that of the Lithuanian study sample (13). Other foreign studies observed a "molar" pattern of tooth emergence $(11,12)$. For Czech girls this "molar" pattern was observed for the left side only, but in both genders the polymorphic variation in the tooth pair lower central incisors/lower first molar is common.

From an orthodontic point of view, it is important that there is no significant polymorphic sequence in tooth pair maxillary premolar/maxillary canine, which is advantageous for interceptive extraction of the first premolar in cases of crowding. The first premolar emerges before the canine in the upper jaw in $97 \%$ in girls and always in boys. The emergence order in the mandible is not advantageous for the interceptive extraction of first premolars, due to the fact that the polymorphic sequence in the tooth pair first premolar/canine occur only in 13\% of girls and not at all in boys. The emergence of the second molar before the second premolar could push mesially the first molar and cause the lack of space for the eruption of second premolar. Our research proved that there is a significant polymorphic sequence in tooth pair second molar/second premolar in either jaws.

\section{CONCLUSION}

In conclusion, our research established the first norms for polymorphic sequences in permanent tooth emergence in Czech children, which could serve as the example of European Caucasians. Our findings may be useful to paediatric dentists and orthodontics as these norms are important for the evaluation and prediction of tooth emergence sequence in individual children.

\section{Acknowledgements}

The study was supported by the project GA UK No 488417, by PROGRES/LF1/Q29 (Charles University, Czech Republic) and by the project 14-37368G (Grant Agency, Czech Republic).

\section{Conflict of Interests}

None declared

\section{REFERENCES}

1. Demirjian A. Dentition. In: Falkner F, Tanner JM, editors. Postnatal growth neurobiology. Boston: Springer; 1986. p. 269-98.

2. Demirjian A, Goldstein H, Tanner JM. A new system of dental age assessment. Hum Biol. 1973;45(2):211-27.

3. Liversidge, H. Variation in modern human dental development. In: Thompson JL, Krovitz GE, Nelson AJ, editors. Patterns of growth and development in the genus Homo. Cambridge: Cambridge University Press; 2003. p. 73-113.

4. Mugonzibwa EA, Kuijpers-Jagtman AM, Laine-Alava MT, van`t Hof MA. Emergence of permanent teeth in Tanzanian children. Community Dent Oral Epidemiol. 2002 Dec;30(6):455-62.

5. Agarwal KN, Gupta R, Faridi MM, Kalra N. Permanent dentition in Delhi boys of age 5-14 years. Indian Pediatr. 2004;41(10):1031-5.

6. Billewicz WZ, McGregor IA. Eruption of permanent teeth in West African (Gambian) children in relation to age, sex and physique. Ann Hum Biol. 1975;2(2):117-28.

7. Diamanti J, Townsend GC. New standards for permanent tooth emergence in Australian children. Aust Dent J. 2003;48(1):39-42.

8. Leroy R, Bogaerts K, Lesaffre E, Declerck D. The emergence of permanent teeth in Flemish children. Community Dent Oral Epidemiol. 2003;31(1):30-9.

9. Smith BH, Garn SM. Polymorphisms in eruption sequence of permanent teeth in American children. Am J Phys Anthropol. 1987 Nov;74(3):289303.

10. Shaweesh AI, Al-Omiri MK, Alsoleihat FD. Variation in time of emergence of permanent teeth among urban and rural Jordanian school children. Saudi Med J. 2011;32(10):1066-72. 
11. Kaur I, Singal P, Bhatnagar DP. Timing of permanent teeth emergence and dental caries among Jatsikh children of public and government schools of Patiala district. Anthropologist. 2010;12(2):141-8.

12. Gaur R, Boparai G, Saini K. Effect of under-nutrition on permanent tooth emergence among Rajputs of Himachal Pradesh, India. Ann Hum Biol. 2011;38(1):84-92

13. Almonaitiene R, Balciuniene I, Tutkuviene J. Standards for permanent teeth emergence time and sequence in Lithuanian children, residents of Vilnius city. Stomatologija. 2012;14(3):93-100.

14. Gates RE. Computation of the median age of eruption of permanent teeth using probit analysis and an electronic computer. J Dent Res. 1966 Jul-Aug;45(4):1024-8.

15. Shaweesh AI. Timing and sequence of emergence of permanent teeth in the Jordanian population. Arch Oral Biol. 2012;57(2):122-30.

16. Shaweesh AI. Polymorphisms in sequence of permanent tooth emergence: a cross-sectional study on Jordanian children and adolescents. Acta Odontol Scand. 2013;71(1):32-7.

17. Vastardis H. The genetics of human tooth agenesis: new discoveries for understanding dental anomalies. Am J Orthod Dentofacial Orthop. 2000;117(6):650-6.

18. Holman DJ, Jones RE. Longitudinal analysis of deciduous tooth emergence: II. Parametric survival analysis in Bangladeshi, Guatemalan, Japanese, and Javanese children. Am J Phys Anthropol. 1998;105(2):209-30.

19. Gopfertová D. Basics of general epidemiology, public health service online learning courses [Internet]. Prague: Charles University, Second Faculty of Medicine, Department of Epidemiology; 2014 [cited 2019 March 28]. Available from: http://www.khshk.cz/e-learning/kurs1a/ publicita.html.
20. Dahlberg AA, Menegaz-Bock RM. Emergence of the permanent teeth in Pima Indian children: a critical analysis of method and an estimate of population parameters. J Dent Res. 1958 Nov-Dec;37(6):1123-40.

21. Adler P. Effect of some environmental factors on sequence of permanent tooth eruption. J Dent Res. 1963;42:605-16.

22. Clements EM, Davies-Thomas E, Pickett KG. Time of eruption of permanent teeth in British children at independent, rural, and urban schools. Br Med J. 1957;1(5034):1511-3.

23. Posen AL. The effect of premature loss of deciduous molars on premolar eruption. Angle Orthod. 1965;35:249-52.

24. Lee MM, Low WD, Chang KS. Eruption of the permanent dentition of Southern Chinese childrenin Hong Kong. Arch Oral Biol. 1965;10(6):84961.

25. Helm S, Seidler B. Timing of permanent tooth emergence in Danish children. Community Dent Oral Epidemiol. 1974;2(3):122-9.

26. Friedlaender JS, Bailit HL. Eruption times of the deciduous and permanent teeth of natives on Bougainville Island, Territory of New Guinea: a study of racial variation. Hum Biol. 1969;41(1):51-65.

27. Virtanen JI, Bloigu RS, Larmas MA. Timing of eruption of permanent teeth: standard Finnish patient documents. Community Dent Oral Epidemiol. 1994 Oct;22(5 Pt1):286-8.

Received October 23, 2017 Accepted in revised form March 28, 2019 